A CRITIQUE OF A METHOD TO DETERMINE LONG-TERM DECLINE OF CORAL REEF ECOSYSTEMS

\author{
by \\ Peter V. Ridd \\ Reprinted from \\ ENERGY \& \\ ENVIRONMENT \\ VOLUME 18 No. 62007
}

MULTI-SCIENCE PUBLISHING CO. LTD.

5 Wates Way, Brentwood, Essex CM15 9TB, United Kingdom 


\title{
A CRITIQUE OF A METHOD TO DETERMINE LONG-TERM DECLINE OF CORAL REEF ECOSYSTEMS
}

\author{
Peter V. Ridd \\ Marine Geophysics Laboratory, School of Mathematics and Physics and I.T., James Cook \\ University, Townsville, 4811,Queensland, Australia (Email: peter.ridd@jcu.edu.au)
}

\begin{abstract}
The supposedly already-degraded state of coral reef ecosystems is sometimes claimed to be a reason why anthropogenic global warming will have a major impact on the reefs, i.e. they are already close to extinction and can easily be tipped over the edge. Recently published work by Pandolfi et al. (2003) in Science has outlined a method for measuring the decline of coral reef ecosystems throughout the world according to which the outer and inner Great Barrier Reef (GBR) are claimed to be $28 \%$ and $36 \%$ respectively, down the path towards ecological extinction. This is a highly significant claim given the important status of the GBR, so the result deserves attention and objective scrutiny.

This paper sets out to scrutinise the methodology used by Pandolfi et al. (2003) under four headings: (i) the guilds are poorly weighted and focus largely on human target species, rather than species that are ecologically important to reefs; (ii) the numerical scale used to "measure" the state of the reefs is not well-founded and hence distorts the result; (iii) the analysis fails to recognize that the GBR is of relatively recent origin and therefore never existed in the pre-human/pristine cultural period as defined by PAN; and (iv) in many cases it is doubtful that the literature cited demonstrates the claimed decline in ecological state.

It is concluded that the work of Pandolfi et al. (2003) cannot be used as justification that the Great Barrier Reef has lost significant resilience, or that it is particularly susceptible to global warming because of its present supposedly degraded state.
\end{abstract}

Keywords: Coral Reef, Ecosystem decline, Anthropogenic effects, Great Barrier Reef.

\section{INTRODUCTION}

There is considerable debate, both in the scientific and in the broader community about anthropogenic influences on the GBR, particularly runoff of nutrients and pesticides from agriculture, and predicted anthropogenic temperature rise. Some claim that the GBR is already seriously degraded (Pandolfi et al., 2003; Wolanski, 2003; Hoegh-Guldberg, 1999). These authors argue that the synergy of different adverse 


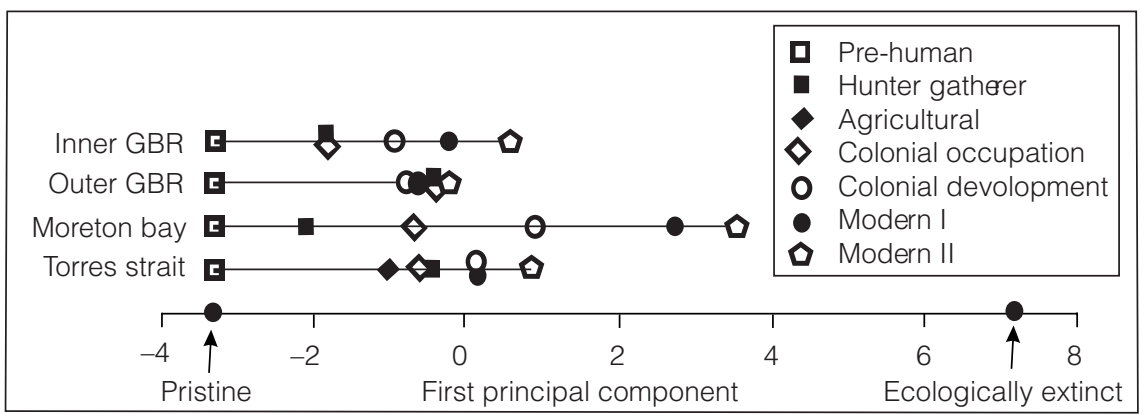

Figure 1: Principal Component Analysis of ecosystem degradation for the Australian reefs based on the ecological state of all seven guilds of reef inhabitants at the 14 locations (after Pandolfi et al., 2003).

influences makes coral reefs particularly susceptible to the impact of global warming. It is not disputed that high water temperature can cause bleaching of the coral polyps. This is a process where the symbiotic algae are ejected from the polyp, in many cases causing death. There is therefore a prima facie case that coral reefs which are already degraded from a range of environmental problems, from over-fishing to runoff of sediment, are perhaps likely to be less resilient to possible future water temperature increases (Hughes et al., 2003).

In order to argue that the worlds reefs are susceptible to stressors such as climate change it is important to develop some measure of the state of the world's coral reef systems. This is not a trivial task however, and to this end, Pandolfi et al. (2003), hereafter referred to as PAN, have formulated a method that is claimed to give an objective measure of the state of the worlds reefs. PAN present a statistical procedure to track the "journey" of the reef ecosystems towards ecological extinction through time. According to their analysis, the outer and inner Great Barrier Reef (GBR) are found to be $28 \%$ and $36 \%$, respectively, down the path towards ecological extinction (Figures 1 and 2). This is a highly significant claim given that the GBR is the world's largest continental reef ecosystem, has World Heritage status, and is of considerable cultural and financial significance to Australia. In the Australian scientific community and public arena, the conclusions drawn by PAN have attracted much interest. Because the paper appeared in a high impact journal, and is authored by eminent and respected scientists, it is likely to be highly influential in setting public policy. For these reasons alone, the methodology and results suggested by PAN deserve attention and scrutiny. In addition, because PAN claims that many of the world's reefs are already highly degraded, including the GBR, there is added impetus to prevent greenhouse gas production, as the influence of warmer water temperature may cause the final collapse of these ecosystems.

After summarizing the PAN methodology, this paper provides a critical analysis of the methodology adopted by PAN and its consequences in four areas. Although most of the comments below will focus on the GBR, many of the conclusions will also be applicable to the other locations considered in PAN. 


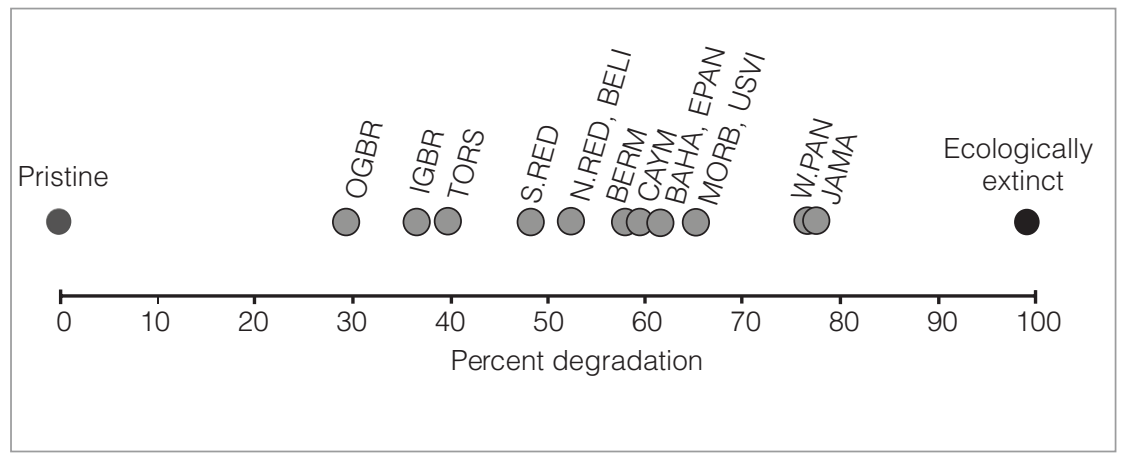

Figure 2: Present ecosystem condition of the 14 reef regions plotted along an axis of ecosystem degradation measured as the relative distance along the first Principal Component between pristine and ecological extinction. BAHA, Bahamas; BELI, Belize; BERM, Bermuda; CAYM, Cayman Islands; JAMA, Jamaica; E.PAN, E. Panama; W.PANW, Panama; USVI, U.S. Virgin Islands; NRED, N Red Sea; S.RED, S Red Sea; IGBR, Inner Great Barrier Reef; OGBR, Outer Great Barrier Reef;

MORB, Moreton Bay; TORS, Torres Strait. (after Pandolfi et al., 2003).

\section{SUMMARY OF PANDOLFI ET AL. (2003) (PAN)}

PAN attempt to document the decline of coral reef ecosystems at fourteen major coral reef regions around the world. These regions are; Bahamas, Belize, Bermuda, Cayman Islands, Jamaica, E. Panama, W. Panama, U.S. Virgin Islands, N Red Sea, S Red Sea, Inner Great Barrier Reef, Outer Great Barrier Reef, Moreton Bay, and Torres Strait.

The health of the coral reef ecosystems was determined by considering seven general categories of biota, (guilds) which share use of some resource such as food or habitat (Table 1). The ecological state of the seven guilds was categorized into six states determined according to the criteria outlined in Table 2. It should be noted that the fifth category, ecologically extinct refers to the situation that the guild is so depleted that it no longer plays an significant role in the ecosystem.

In order to apply statistical analysis, the ecological states were assigned a numerical descriptor from 1 (pristine) to 6 (globally extinct). It is important to note that the ecological "journey" from pristine to globally extinct is divided into five equal steps., and the journey from pristine to ecologically extinct is divided in four steps. Because the intention of PAN was to plot trends in the decline of coral reef ecosystems over long time periods, the ecological state of the guilds were determined for seven cultural periods which are broadly defined in Table 3. Using a variety of sources, both scientific literature and elsewhere, a data matrix was constructed showing the change in time of the ecological state of the guilds. An example of the data matrix for the Outer GBR is shown in Table 4.

A principal component analysis was used to ordinate the data to describe the historical trajectories of change in the health of the coral reef ecosystems. In doing 
Table 1: The seven guilds used to determine the health of coral reef ecosystems together with common examples of species found within each guild

Guild

Common Examples

Large Herbivores

Large Carnivores

Small Herbivores

Small Carnivores

Corals

Seagrass

Suspension Feeders
Sea Cow, Green Turtle, Bump Head Parrot Fish

Sharks, Crocodiles, Monk Seals, Loggerhead and Hawksbill turtles, Barracuda, Large Groupers

Most Parrotfish, Sea Urchins

Most fish and invertebrates

Sponges, Oysters, Trochus

Table 2: Ecological states of guilds, numerical descriptors, and criteria used to assess the 14 tropical marine sites analyzed

\begin{tabular}{|c|c|c|}
\hline Ecological State & Numerical descriptor & Criteria for classification \\
\hline Pristine & 1 & $\begin{array}{l}\text { Detailed historical record of marine resource } \\
\text { lacks any evidence of human use or damage }\end{array}$ \\
\hline Abundant/common & 2 & $\begin{array}{l}\text { Human use with no evidence of reduction of } \\
\text { marine resource. }\end{array}$ \\
\hline Depleted/uncommon & 3 & $\begin{array}{l}\text { Human use and evidence of reduced } \\
\text { abundance (number, size, biomass, etc.) }\end{array}$ \\
\hline Rare & 4 & Evidence of severe human impact. \\
\hline Ecologically extinct & 5 & $\begin{array}{l}\text { Rarely observed and further reduction would } \\
\text { have no further environmental effect. }\end{array}$ \\
\hline Globally extinct & 6 & No longer in existence \\
\hline
\end{tabular}

so, PAN are compressing the seven individual guild states into a single numerical index. An example of the trajectories of change for the Australian reef ecosystems is shown in Figure 1. It can be seen from Figure 1 that the outer Great Barrier Reef (GBR) moves from pristine in the pre-human period, to around one third of the way along the first principal component (PC1) axis towards ecological extinction in the hunter-gatherer period, and shifts little thereafter through time. The trajectory for Moreton Bay on the other hand shows a steady progression to two thirds of the way along the PC1 axis towards ecological extinction. The final state of all the fourteen sites is expressed in terms of percent degradation (Figure 2) from pristine, and despite the outer GBR being the least degraded reef system, it is nevertheless considered to be about $28 \%$ degraded by this measure. The inner GBR and Torres Straits reefs are rated at $36 \%$ and $40 \%$ degraded respectively. The heavily damaged Caribbean reefs are determined as being at least 50\% degraded, and Moreton Bay is $65 \%$ degraded. 
Table 3: Properties of the respective cultural periods

Cultural Period

Pre-human $(40,000$ bp - 1609)

Hunter-gatherer (20000 bp - 1824)

Agricultural based (3500 bp - 1800)

Colonial Occupation (1500-1800)

Colonial development (1800-1900)

Modern I (1900-1950)

Modern II (1951-2002)
Properties

No evidence of, or insignificant, human exploitation; pristine ecosystems with only natural perturbations. No permanent settlements and no major surplus for trade; no major system for distribution and exchange over large areas.

People cultivated crops and raised livestock, so they could stay in one location. Agriculture enabled development of an economy, permanent settlements, and a culture.

Spread of western values. Opening of sea-lanes and commencement of trade with the west. Catch more than needed for own consumption, develop techniques for storage and transport, ship surplus to neighbors (up country, next village, etc,) exchange with barter.

People become centralized into large, metropolitan cities. "Development" is defined as developing the colonies natural resources and mining sectors for use by their imperial owners.

Distance no object; consumer preference starts to drive product development.

Technologies advances.

Globalization of markets. Establishment of free trade zones.

\section{PROBLEMS AND CONSEQUENCES OF THE PAN METHODOLOGY}

There are four issues where detailed scrutiny of the methodology adopted by PAN is warranted:

1. Inappropriate weighting of the guilds.

2. Inappropriate scale for measuring ecological state.

3. The analysis fails to recognize that the GBR never existed in the pre-human/ pristine cultural period.

4. In many cases it is doubtful that the literature cited shows the claimed decline in ecological state.

These four problems are discussed individually below.

\subsection{Problem 1: Effect of Weighting of the Guilds}

The problem with equal weighting of the guilds is that the fundamental importance of corals to coral reef ecosystems is not adequately recognized. Corals are only weighted 
Table 4: An example of the data matrix of the ecological state for each of the seven guilds during each of the 7 cultural periods, in this case for the outer Great Barrier Reef. Similar matrices were constructed for the other 13 locations

\begin{tabular}{|c|c|c|c|c|c|c|c|}
\hline \multirow[b]{2}{*}{ Cultural Period } & \multicolumn{2}{|c|}{ Carnivores } & \multicolumn{2}{|c|}{ Herbivores } & \multirow[b]{2}{*}{ Coral } & \multirow[b]{2}{*}{ Sea-grass } & \multirow{2}{*}{$\begin{array}{c}\text { Suspension } \\
\text { Feeders }\end{array}$} \\
\hline & Large & Small & Large & Small & & & \\
\hline Pre human & 1 & 1 & 1 & 1 & 1 & N/A & 1 \\
\hline Hunter Gatherer & ND & 1 & ND & ND & ND & N/A & ND \\
\hline Agriculture & N/A & N/A & N/A & N/A & N/A & N/A & N/A \\
\hline Colonial & & & & & & & \\
\hline $\begin{array}{l}\text { Occupation } \\
\text { Colonial }\end{array}$ & ND & 1 & ND & ND & ND & N/A & ND \\
\hline Development & ND & 1 & 2 & 2 & ND & N/A & ND \\
\hline Modern 1 & 2 & 2 & 2 & 2 & ND & N/A & ND \\
\hline Modern 2 & 3 & 2 & 2 & 2 & 2 & N/A & ND \\
\hline
\end{tabular}

N/A means that the cultural period or guild did not occur at that locality. ND means that no data exist to evaluate guild state.

as $1 / 7^{\text {th }}$ of the coral reef ecosystem. PAN's methodology implicitly gives equal weighting to all seven guilds and this implicit use of equal weights has some unreasonable consequences. For example, seagrasses are given equal weight to corals. Although seagrasses are doubtless an important component of some coral ecosystems it is unreasonable to give them an equal weighting as corals. There are many coral reefs around the world that do not have significant sea grass beds (e.g. the outer GBR) and thus it is difficult to argue that seagrasses are of fundamental importance to reefs. Most major seagrass beds in the inner GBR are found well away from coral reefs, and it is unclear how these guilds affect coral reef ecosystems. It is important not to downplay the importance of seagrass ecosystems as they are known to play an important role as habitats for many species of fish and crustaceans, which may be ecologically linked to coral reefs (Coles et al., 1987). However, seagrasses are obviously of fundamental importance to seagrass ecosystems, but are not of such fundamental importance to reef building corals. Conversely, corals are obviously of fundamental importance to coral reefs.

Another unreasonable consequence of PANs method is that it gives equal weight to large herbivores (comprised of dugongs and some turtles) and corals. Although the large herbivores are a significant component of many coral reef ecosystems, and their decline or loss is by itself cause for serious concern, no evidence is presented to support the proposition that they are of equal importance to coral reefs. It should be noted that there is no evidence for a major role of turtles or dugongs in coral reefs, as opposed to seagrass beds (where these herbivores could be/could have been significant). Dugongs, for example, probably never existed in many reefs around the world (e.g. remote mid ocean island reefs), and are rare in the outer GBR perhaps because of lack of seagrasses. There is no evidence in PAN that Bump-head parrot fish have declined in numbers. The importance of the large herbivore guild may also be 
Table 5: An alternative weighting system for the guilds

\begin{tabular}{lcc} 
Guild & PAN's Weighting & Alternative Weighting \\
\hline Large Herbivores & 1 & 0.1 \\
Small Herbivores & 1 & 2.0 \\
Large Carnivores & 1 & 0.1 \\
Small Carnivores & 1 & 0.5 \\
Corals & 1 & 4 \\
Seagrasses & 1 & 0.1 \\
Suspension Feeders & 1 & 0.2 \\
\hline
\end{tabular}

exaggerated for Australian reefs because the ecological role of the larger and more spectacular herbivores may well be taken up in their absence by smaller herbivores. There is effectively no fishery for small herbivores in Australia. In summary, coral reef ecosystems can exist without large herbivores, but coral reefs cannot exist without reef-building corals.

Similarly, it is doubtful that the sponges, oysters, and trochus that make up the suspension feeder guild in a reef ecosystem have the same importance as corals.

The equal weighting used in PAN fails to recognize the central importance of reef-building corals and also of small herbivores in coral reef ecosystems. It has been well established that small herbivores play a fundamental role in the prevention of a phase change to an algal dominated community (Hughes, 1994). Corals and small herbivores should thus be the dominant guilds in any analysis of a coral reef ecosystem functioning.

It might be argued that the proposition that small herbivores are a dominantly important guild is a modern perspective that results from shifting baselines: the large herbivores are now gone, so we are all deluded that small herbivores are more important. For Australian reefs however there is no evidence to support this argument.

A notable feature of the species represented by the guilds is that they are comprised heavily of species subject to human exploitation through hunting and collection. The result is that the measure of degradation is not a measure of the ecological damage to the reef, but is rather a measure of the degradation of a resource, i.e. a measure of the economic and cultural reduction in value as a fishery. It would be legitimate to focus on economic and cultural aspects of the reef ecosystem if the main aim of PAN was not the measurement ecological decline.

Because the guilds and species that are subject to human exploitation (e.g. large herbivores) are often in worse state than corals, their high weighting exaggerates the apparent decline of the ecosystem. This is particularly true of the Torres Strait and the inner GBR, where the ecological state of the corals is classified by PAN as being Abundant/Common (i.e. "no evidence of reduction of marine resource"), but the ecological state of some of the other guilds in these regions are rated as depleted.

The question remains: what would be a more appropriate weighting of the guilds? The decision might ultimately be subjective in the absence of reliable field data, but it must reflect the relative importance of each of the guilds to the coral reef ecosystem. Table 5 proposes an alternative weighting that could be attributed to each guild. In this 


\section{Table 6: The relative contribution to the journey from pristine to ecologically extinct for each transition of ecological state. PAN implicitly uses equal transitions}

\begin{tabular}{lcc}
$\begin{array}{l}\text { Ecological State } \\
\text { Transition }\end{array}$ & $\begin{array}{c}\text { \% of journey to ecological } \\
\text { extinction (PAN) }\end{array}$ & $\begin{array}{c}\text { \% of journey to ecological } \\
\text { extinction (alternative scheme) }\end{array}$ \\
\hline Pristine to Abundant (1-2) & $25 \%$ & $5 \%$ (maximum) \\
Abundant to Depleted (2-3) & $25 \%$ & $65 \%$ \\
Depleted to Rare (3-4) & $25 \%$ & $20 \%$ \\
Rare to Ecologically extinct (4-5) & $25 \%$ & $10 \%$ \\
\hline
\end{tabular}

scheme, corals are rated as being more important than the sum of all other guilds, twice as important as small herbivores, and 40 times more important than large herbivores, large carnivores and seagrasses. This scheme emphasizes the fundamental importance of corals, small herbivores, and also small carnivores to the coral reef ecosystems. Other weighting schemes could be equally defensible. An important point is that by weighting the guilds differently to PAN, a different result can be obtained in the analysis, especially if the corals in the ecosystem are better in condition than the other guilds.

\subsection{Problem 2: Inappropriate Scale for Measuring Ecological State}

The simple numerical scale used in PAN (Table 2) to signify the ecological state has a profound influence on the results. It implies that the journey from pristine to ecological extinction occurs in four equal steps as shown in Table 6.

Based on the definitions used in PAN, it is unreasonable to give each transition equal weight. The transition from state 1 to 2 is defined as a step from a "pristine" environment to "no evidence of reduction of marine resource". This is a much smaller ecological shift than from state 2 to 3 , "no evidence of reduction of marine resource" to "depleted/uncommon". According to PAN even a negligible human use of the resource would mean that the ecological state cannot be classed as pristine and thus the ecological state has moved $25 \%$ of the way to ecological extinction. Intuitively it is clear that the journey from abundant to depleted should be much greater than the journey from pristine to abundant as in this case, there is a shift from a very healthy ecosystem to one showing significant signs of trouble.

In the case of the GBR, the finding that it has moved $25 \%$ of the way to ecological extinction is merely a consequence of most of the guilds moving from pristine to abundant. No sophisticated statistical analysis is necessary to arrive at this conclusion. To the contrary, the sophisticated principal component analysis masks the implicit assumption that pristine to abundant represents $25 \%$ of the journey towards extinction.

An alternative scheme to represent the relative contribution of the journey from pristine to ecologically extinct for each transition of ecological state is shown in Table 6. Again, there is a degree of subjectivity in the assignment of the values for each transition. However, the proposed values recognize that the journey from 
pristine to abundant is much less than the journey from abundant to depleted . If these transitions are used together with the modified weighting for the guilds (Table 5), both the inner and outer GBR would be at most $5 \%$ of the way to ecological extinction.

\subsection{Problem 3: Failure to Appreciate that the GBR Never Existed in Pre-human Times}

At the last glacial maximum around 18000 years ago, sea level was around $120 \mathrm{~m}$ lower than today, large areas of the Queensland continental shelf were exposed and the coastline advanced seaward by up to $200 \mathrm{~km}$. Wide scale carbonate production and reef building was reinitiated on the GBR by approximately 12000 years ago, upon a dramatic rise in sea level at the end of the last glaciation (Dunbar and Dickens, 2003). Aboriginal settlement of Australia, and presumably the coastal plains of central and northern Queensland predate the formation of the GBR by at least 20000 years and thus, the GBR in its present configuration at no stage existed in the pre-human period, i.e. the first row of table 4 referring to the pre-human period is not applicable and should not be given a pristine (1) state. It follows, that the $25 \%$ shift from the pre-human to later periods never occurred. By PAN's analysis, the ecological state of the outer GBR did not decline significantly in modern times. The corollary is that by PAN's analysis, the outer GBR (i.e. the overwhelming proportion of the GBR) has not changed significantly since its formation in the hunter gatherer period.

\subsection{Problem 4: The Cited Literature Often does not Justify Conclusions about the Decline in Ecological State}

PAN uses references of other studies and observations to justify their decisions of the ecological state in the data matrix. Unfortunately however, in many cases the literature does not justify the claims of system degradation. A similar comment is made by Aronson and Precht (2006) in partial reference to PAN when they warn against accepting unsupported claims about ecological effects. In the analysis that follows, and in the interests of brevity, this critique will consider only the literature cited regarding the important guilds (corals, small herbivores and small carnivores) for the GBR.

\subsubsection{Inner Great Barrier Reef References}

PAN cited Benham (1951) as documenting the corals of the inner GBR moving 25\% towards ecological extinction between the Colonial Development and Modern I periods. Benham(1951) is a book entitled "Diver's Luck-A story of Pearling Days". It is not explained in PAN how this reference, can be used to substantiate that the corals were $25 \%$ degraded. Certainly no such comment is made by Benham (1951). Moreover, Benham (1951) is a non-scientific or anecdotal source. Certainly these sources must not be discounted and can yield very useful information. However, great care must be taken not to place too much reliance on anecdotal information which is not subjected to the process of peer-review, and rarely will include carefully documentation of methods and the reliability of measurements over time, characteristic of a scientific study. 
PAN cites Richmond (1993) and Wollston (1995) to substantiate the claim that the corals of the inner GBR are 25\% of the way to ecological extinction. Richmond (1993) is a review paper about anthropogenic impacts on corals around the world. However, no data are presented that could justify that the corals of the inshore GBR are degraded to such an extent. Additionally no such conclusion was drawn or implied by Richmond (1993). Wollston (1995) is a work entitled "A Few Anecdotes from 60 years Ago in Nth. Qld." and it is not clear how this reference supports the claim made by PAN. It could be argued that anecdotal evidence can legitimately be used to determine if a guild is no longer pristine as by PAN's definition any minor human perturbation of the system renders it non pristine. However, as PAN defines the decline from Pristine to Abundant as representing a $25 \%$ decline, then a higher standard of proof than this anecdotal evidence is required. In conclusion, these references provide no data to support the proposition that the inner GBR reefs are $25 \%$ of the way to ecological extinction. Indeed, no such data exists in the literature.

PAN cites Barker (1993) and Beaton (1985) as demonstrating that the small herbivores of the inner GBR are $25 \%$ of the way to ecological extinction from the prehuman to hunter-gather period. It is not stated how these articles were used to substantiate this claim but is presumably referenced to demonstrate that Aboriginal communities that lived along the coast of Queensland used the marine resource. It is not clear how this can be converted to a quantitative statement that the small herbivores were hunted to such an extent.

PAN cites several references to claim that the small carnivores of the inner GBR have moved $25 \%$ of the way to ecological extinction (Banfield, 1908; Fitzgerald, 1982; Hobson et al., 1985; Hall, 1982). It is not clear on what basis that this claim was made. These articles are largely about indigenous hunting, but could not be regarded as references that give useful quantitative information on the historical depletion of the fishery. It is true that there is significant exploitation of some carnivorous fish such as coral trout, and some of these species may be significantly depleted although the data is limited and heavily biased towards those species subject to human exploitation.

\subsubsection{Outer GBR References}

PAN claim that the outer GBR is now $28 \%$ degraded. This conclusion was made on the basis of 16 references, 13 of which could be classed as popular literature or unrefereed reports, and only 3 are publications in scientific journals. Two of the three genuinely scientific papers (Paterson et al., 1994, and Paterson, 1990) relate to Humpback whales and the shark fishery, both of which are species that have minor relevance to the reef. Accordingly, only one scientific article (Hopley, 1988) was used to support the conclusion that the outer GBR is $25 \%$ of the way to ecological extinction.

Hopley (1988) is a general paper on the anthropogenic impact of the GBR and discusses numerous threats to the GBR-shipping, crown-of-thorns starfish, and agricultural runoff. Hopley (1988) cites no quantitative data that might support a claim that the outer GBR is $25 \%$ of the way to ecological extinction. Furthermore, a large amount of research has occurred since Hopley (1988) was written. None of the subsequent research has unequivocally demonstrated that there has been a significant 
long-term reduction in coral cover, species diversity, or coral health on a significant part of the outer GBR. It is true that crown-of-thorns starfish have caused temporary damage but it is debatable whether such outbreaks have increased in their reoccurrence or severity since European settlement (Walbran et al., 1989). In addition, coral bleaching has affected many parts of the GBR for short periods, and there is considerable doubt regarding the long-term impact of past warming on the quality or quantity of corals assemblages on the reef (Hughes et al., 2003).

PAN use seven unrefereed articles to support the claim that the small herbivores of the outer GBR are $25 \%$ of the way to ecological extinction. No supporting data that might elucidate this claim are shown by PAN. That the small herbivores are $25 \%$ of the way to ecological extinction is a surprising conclusion considering that there is no commercial or amateur fishery of small herbivorous fish, except on a very small scale for the aquarium trade.

PAN uses 3 unrefereed articles to support the conclusion that the small carnivores of the outer GBR are $25 \%$ of the way to ecological extinction. Again it is unclear how these references support this conclusion and a similar commentary could be made for this region as was made above for the small carnivores of the inner GBR.

As a final comment, it us unclear how PAN have made the decisions regarding the ecological state of the guilds.

\section{RE-EVALUATION OF THE STATE OF THE GREAT BARRIER REEF}

In light of the previous discussion, a range of results of the state of Australia's reefs can be produced using PAN's methodology depending upon what weight one uses for the guilds and, more importantly, on the numerical scale used to represent the ecological state of the guilds. It should be added that converting categorical data such as the ecological state and assigning it a numerical value for use in mathematical analysis is fraught with difficulties because of the subjectivity of the assignment of the numerical values. In this re-evaluation the values in the second column of table 6 are used where the change from the pristine state to the abundant state is rated as only $5 \%$ (max.) of the full journey to ecological extinction. Using the modified guild weight presented in Table 5, where corals are weights much more heavily than other guilds, then by PAN's analysis, the outer GBR is less than $6 \%$ of the way to ecological extinction. If one takes into account that the GBR has never existed without human occupation close-by, then one can conclude that the degradation of the outer GBR since European settlement is around $1 \%$.

This small amount of degradation must be viewed with caution because it uses an analysis which relies on a subjective methodology with significant inherent problems. Nevertheless, the general conclusion that the Great Barrier Reef is in excellent state is reasonable. The Great Barrier Reef is a very large system, $2000 \mathrm{~km}$ in length and adjacent to a very small coastal population of less than 0.5 million. The Caribbean Reefs are adjacent to populations of over 50 million. Most of the GBR is rarely visited because it is over $50 \mathrm{~km}$ from the coast, in contrast to the Caribbean reefs. The large distance of most of the GBR from the coast greatly mitigates the influence of enhanced river runoff due to poor agricultural practices. The only fishery on the GBR is of carnivorous species; the intensive fishing practices of herbivorous 
species in the Indo-Pacific or Caribbean reefs do not occur on the GBR. The Northern half of the GBR is extremely remote with a coastal population of a few thousand people over almost a thousand kilometers or coastline. In many regards, the GBR is the best protected, most pristine and remote ecosystem on earth with the exception of only Antarctica.

\section{CONCLUSION}

It is sometimes claimed that synergistic effects of a combination of factors will ultimately cause the demise of the world's reefs. In order to determine how close our reefs are to ecosystem collapse, and how global warming might influence them, it is useful to develop an objective method of measuring the present state of our reefs.

PAN's attempt to do this has four main problems i.e (i) it weights guilds of minor ecological importance equally to those of fundamental importance to the functioning and survival capacity of coral reef ecosystems. (ii) It uses an over-simplistic counterintuitive numerical scheme to describe the ecological state of the guilds. This scheme implicitly makes the transition from pristine to abundant to represent $25 \%$ of the journey to ecological extinction. (iii) The Australian reefs never existed in a prehuman, pristine state. The overriding implication of this is that the GBR has not changed significantly since its formation during Aboriginal occupation. (iv) The literature cited is scant and relies heavily on un-refereed publications, from which it is unclear, and unexplained, how quantitative ecological state was deduced for the individual guilds.

PAN's attempt to develop a method to gauge the state of particular coral reef ecosystems is a commendable attempt to tackle a difficult and important problem. It is a good basis from which further analyses can be made but in its present form it provides a misleading impression that the state of some of the reef systems cited are in a much worse situation than they are.

\section{ACKNOWLEDGEMENTS}

Dr Alan Orpin is particularly thanked for improving the manuscript and Max Beran provided invaluable commentary and criticism.

\section{REFERENCES}

Aronson, R.B., and W.F. Precht 2006. Conservation, precaution, and Caribbean Reefs. Coral Reefs. 25, 441-450.

Banfield, E.J. 1908. Blacks as fisherman: expedients, devices, strategems. Queensland Geographic Journal 24:43-62.

Barker, B.C. 1993. Early human exploitation of island environments within the Great Barrier Reef Marine Park. Reef Research (GBRMPA). Townsville, Queensland. Report 3(3):13-14.

Beaton, J.M. 1985. Evidence for a coastal occupation time-lag at Princess Charlotte Bay (north Queensland) and implications for coastal colonisation and population growth theories for Aboriginal Australia. Archaeology in Oceania 20(1):1-20.

Benham, C. 1951 Diver's Luck-A Story of Pearling Days. Halstead Press Pty. Ltd, Sydney. 258 pages. 
Coles, R. G., Lee Long, W. J., Squire, B. A., Squire, L. C., and Bibby, J. M. (1987) Distribution of seagrasses and associated juvenile commercial prawns in northeastern Queensland waters. Aust. J. Mar. Freshwater Res. 38, 103-119.

Dunbar, G.B. \& G.R. Dickens "Massive siliciclastic discharge to slopes of the Great Barrier Reef Platform during sea-level transgression: New constraints from cores between 15 and $16^{-} \mathrm{S}$ latitude." Sedimentary Geology, 162 (2003): 141-158.

Fitzgerald, R. 1982. History of Queensland from the Dreaming to 1915. University of Queensland Press, St Lucia, Queensland. 354 pages.

Hall, J. 1982. Sitting on the crop of the bay: An historical and archaeological sketch of Aboriginal settlement and subsistence in Moreton Bay, southeast Queensland. Pages 79-95 in S. Bowdler, ed.Coastal Archaeology in Eastern Australia: Proceeding of the 1980 Valla Conferenece on Australian Prehistory. Occasional Papers in Prehistory 11. Australian National University, Canberra.

Hobson, I.,L. Rosendale, J. Johnson, B. Barlow, E. Bunn, E. Bani, E.Mabo, G. Friday, T. Johnson, and J. Davey 1985. Traditional knowledge within the communities-Great Barrier Reef communities. Pages 42-53 in Gray, F. and L. Zann, eds.Traditional knowledge of the marine environment in Northern Australia, Workshop series no. 8, part B, GBRMPA, Townsville, Queensland.

Hoegh-Guldberg, O., (1999). Climate change, coral bleaching and the future of the world's coral reefs.Mar. Freshwater Res., 50, 839-66.

Hopley, D. 1988. Anthropogenic influences on Australia's Great Barrier Reef. Australian Geographer 19(1):26-45.

Hughes, T.P., 1994, Catastrophes Phase Shifts, and Large-Scale Degradation of a Caribbean Coral Reef, Science, 265, 1547-1551.

Hughes, T.P., Baird, A.H., Bellwood, D.R., Card, M., Connolly, S.R., Folke, C., Grosberg, R., Hoegh-Guldberg, O., Jackson, J.B.C., Kleypas, J., Lough, J.M , Marshall, P., Nystrîm, M., Palumbi, S.R., Pandolfi, J.M., Rosen, B. and Roughgarden, J. 2003, Climate Change, Human Impacts, and the Resilience of Coral Reefs, Science, 301, 929-933.

Pandolfi, J.M., Bradbury, R.H., Sala, E., Hughes, T.P., Bjorndal, K.A., Cooke, R.G., McArdle, D., McClenachan, L., Newman, M.J.H., Paredes, G., Warner, R.R., Jackson, J.B.C., 2003. Global trajectories of the long-term decline of coral reef ecosystems. Science, 301: 955-958.

Paterson, R., P. Paterson, and D.H. Cato. 1994. The status of humpback whales Megaptera novaeangliae in East Australia thirty years after whaling. Biological Conservation 70(2): 135-142.

Paterson, R.A. 1990. Effects of long-term anti-shark measures on target and non-target species in Queensland, Australia. Biological Conservation 52: 147-159.

Richmond, R.H. 1993. Coral reefs: present problems and future concerns resulting from anthropogenic disturbance. American Zoologist 33: 524-536.

Walbran, P.D., R.A. Henderson, J.W. Faithful. H.A. Polach, R.J. Sparks, G. Wallace and D.C. Lowe 1989 Crowns-of-thorns starfish outbreaks on the Great Barrier Reef: a geological perspective based upon the sediment record. Coral Reefs 8: 67-78. 
Wollston, F. 1995. A Few Anecdotes from 60 Years Ago in Nth. Qld. F Wollston, Queensland, 111 leaves.

Wolanski, E., R.Richmond, L.McCook and H.Sweatman (2003). Mud, marine snow and coral reefs. American Scientist. 91, 44-51. 